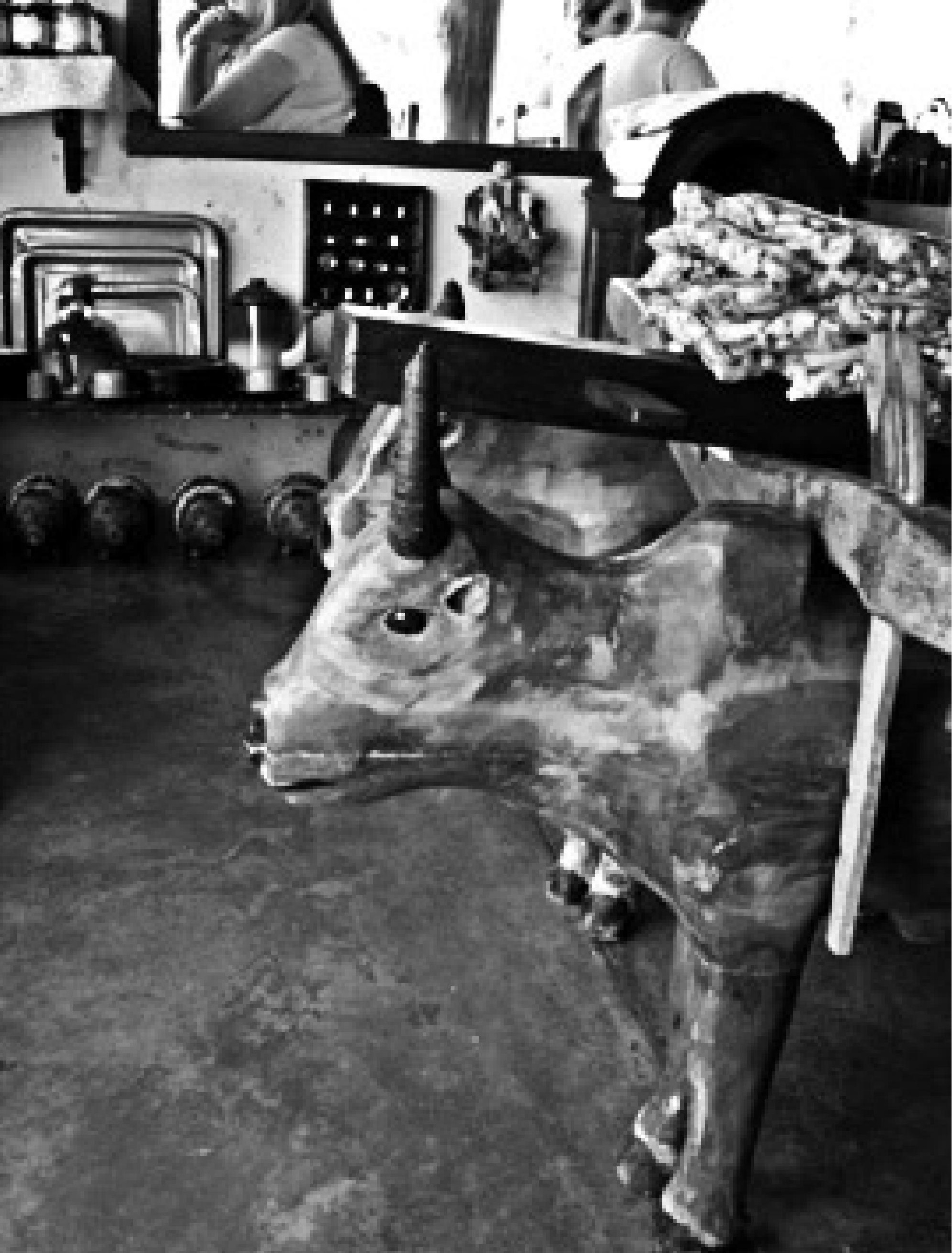




\title{
A Gastronomia Regional e o Turismo como Elementos Fortalecedores da Identidade Cultural Frente à Tensão entre o Global e o Regional
}

The Regional Gastronomy and Tourism as Strengtheners Elements of Cultural Identity Facing the Tension Between Global and Regional

\author{
Everton Luiz Simon ${ }^{1}$ \\ Virginia Elisabeta Etges ${ }^{2}$ \\ Sarah Marroni Minasi ${ }^{3}$
}

1 Doutorando em História na Universidade do Vale do Rio dos Sinos - UNISINOS. Mestre em Desenvolvimento Regional pela Universidade de Santa Cruz do Sul - UNISC. Professor do departamento de História e Geografia; vinculado aos cursos Superiores de Tecnologia em Gastronomia e Gestão de Eventos da UNISC.

2 Doutora em Geografia, Docente e Coordenadora do Programa de Pós-Graduação em Desenvolvimento Regional - UNISC.

3 Mestre em Desenvolvimento Regional pela Universidade de Santa Cruz do Sul - UNISC. Turismóloga. Professora da Faculdade de Administração e de Turismo da Universidade Federal de Pelotas - UFPEL 


\section{RESUMO}

Este artigo tem por finalidade refletir sobre a importância e a influência da cultura, voltada à análise da gastronomia regional, considerando a tensão atual verificada entre o global e o regional e sua relação com a alimentação, a gastronomia e o turismo. Nas transformações promovidas pelo desenvolvimento do capitalismo, entendemos que existem forças homogeneizantes que atuam nos mais distintos territórios. Estas forças provocam uma série de transformações nos territórios em que se inserem, produzindo tendências à padronização, seja nas formas de processamento de atividades produtivas e econômicas, seja nos costumes e hábitos cotidianos das pessoas. Procuramos, desse modo, debater a relação entre alimentação, culinária típica e turismo, enquanto elementos potenciais para o fortalecimento das identidades territoriais, constituintes do patrimônio cultural regional; enquanto elementos importantes para a conformação do aspecto regional, como uma força contra-homogeneizante. Portanto, ao preservar o patrimônio cultural e valorizar a identidade, o lugar estabelece conexão com a dinâmica global, através da atividade turística, fortalece, localmente, seus laços com a sua cultura.

Palavras-chave: Gastronomia regional. Turismo. Desenvolvimento regional.

\section{ABSTRACT}

This article aims to reflect on the importance and the reflection the influence of culture, dedicated to the analysis of the regional cuisine, which considers the current tension between the global and the regional and their relationship with alimentation, gastronomy and tourism. In the transformations promoted by the development of capitalism, we understand that there are homogenizing forces that act in more distinct territories. These forces cause series of transformations to the territories in which, producing the standardization trends, whether in the forms of productive activities and economic processing in customs and daily habits of the people. We seek, therefore, to discuss the relationship between alimentation, typical cuisine and tourism, as potential elements for the strengthening of territorial identities, constituents of the regional cultural heritage. And while important elements for the conformation of the regional aspect, as a contra homogenizing force. Therefore, by preserving cultural heritage and valuing the identity the place connects to the global dynamics, through tourism, and strengthens locally their ties with their culture.

Keywords: Regional cuisine. Tourism. Regional development.

\section{INTRODUÇÃO}

A reflexão sobre cultura, voltada à análise da culinária tradicional, considerando a tensão atual verificada entre o global e o regional, parece-nos, cada vez mais, uma 
atividade importante e complexa. Com uma grande diversidade de conceitos e entendimentos, o aspecto cultural sempre foi um marco peculiar de cada sociedade e tem caracterizado distintos momentos da história da humanidade. Contudo, através do uso de novos recursos tecnológicos e meios de comunicação, da conformação do padrão econômico produtivo, amplificado no período técnico-científico-informacional, são produzidos novos hábitos, os quais são expandidos e assimilados com extrema rapidez.

No contexto das transformações promovidas pelo desenvolvimento do capitalismo, entendemos que existem forças homogeneizantes que atuam nos mais distintos territórios. Estas forças provocam uma série de transformações nos territórios em que se inserem, produzindo tendências à padronização, seja nas formas de processamento de atividades produtivas e econômicas, seja nos costumes ou hábitos cotidianos das pessoas.

Nessa conjuntura, a cultura tradicional, aquela que possui raízes históricas, acaba sendo modificada pela cultura de massa produzida e vendida pela sociedade globalizada. São produzidas séries de mecanismos com apelo para novos hábitos, geralmente indutores do consumo e, principalmente, novos padrões de comportamento. Toda esta produção tem uma intencionalidade e se materializa na modificação dos hábitos cotidianos destas, e, por conseguinte, na alteração da própria identidade cultural.

A influência na formação das identidades acontece por meio de transformações aceleradas da indústria e dos padrões de consumo, alimentados pela presença aguçada do modo de produção capitalista. Isto é, os processos de globalização repercutem diretamente na sociedade, resultando em alterações desde o curto prazo, movidas pela consolidação dos processos de "modernização".

Nascem ações de resistência, caminhos que procuram a afirmação das identidades culturais frente à tensão entre o global e o regional como resultantes do processo de globalização. Esta torna-se uma forma de integração diferenciada e desigual.

O turismo, como fenômeno social, oportuniza aproximação entre culturas diferentes e não pode ser isolado das discussões sobre os processos de formação das identidades. $\mathrm{O}$ fato da atividade turística estabelecer contato entre diferentes culturas, em um espaço geograficamente delimitado, influencia e confere pluralidade ao processo de formação das identidades.

Reconhecer a presença de ordens dialéticas provenientes do fenômeno da globalização é fundamental para abordar uma outra globalização. A transformação das ações centradas no capital para ações focadas no homem permitem o melhor desempenho destinado à preservação do patrimônio e das identidades culturais. 
Dessa forma, o turismo cultural, em seu turno, prioriza as particularidades das expressões da cultura, buscando sempre a qualidade dos atrativos em detrimento da quantidade e padronização. Entende-se essa modalidade como a utilização de aspectos da identidade cultural presente em uma região vocacionada para o turismo.

Assim, nesse contexto, propomos realizar, nesse artigo, uma contextualização, buscando revelar elementos que proporcionam entendimento acerca da importância e da necessidade de valorização de determinadas atividades produtivas; refletindo sobre esses elementos, frente às transformações promovidas pelo modelo econômico capitalista e suas tensões decorrentes no respectivo território. Procuramos, desse modo, debater a relação entre a alimentação, a gastronomia típica e o turismo, enquanto elementos potenciais para o fortalecimento das identidades territoriais, constituintes do patrimônio cultural regional; enquanto elementos importantes para a conformação do aspecto regional, como uma força contra-homogeneizante.

Para tanto, os procedimentos metodológicos utilizados para o desenvolvimento do estudo expresso no artigo se configuram em uma combinação entre procedimentos interpretativos e descritivos, de modo a buscarmos a compreensão crítica das informações coletadas, de caráter qualitativo. Para isso, nos valemos de pesquisa bibliográfica, buscando sistematizar, através da reflexão de vários autores e da análise da realidade vivida no contexto atual, a importância da culinária típica regional como fator de preservação da identidade regional e como potencialidade para o desenvolvimento do turismo regional.

Dessa forma, constatamos que o desenvolvimento do capitalismo, em escala mundial, pode ser considerado como um condutor de tensões nos territórios regionais, visto que a ordem capitalista global segue uma lei única, enquanto a ordem regional é constituída pela associação entre pessoas e objetos no território e, como território, é regido pela interação. Enquanto lei única, o desenvolvimento e expansão do capitalismo se realizam por meio da ação das empresas que transcendem territórios em busca de aspectos mais vantajosos aos seus interesses. Está presente a realização de ações que asseguram a existência de um mercado global, que se sobrepõe aos territórios apropriados pelas sociedades, ou seja, realizam-se, portanto, através da territorialização dos interesses dos segmentos hegemônicos.

Nesse contexto, modificações significativas são notadas nos modos de produção de alimentos, o que provoca uma série de transformações, tanto nas formas de organização dos sistemas produtivos no meio rural, quanto nas formas de processamento e oferta de alimentos nos centros urbanos; e, consequentemente, essas transformações também refletem no processo de formação das identidades. 
Posteriormente, considerando a produção agropecuária e buscando contextualizar a tensão existente entre o global e o regional, elementos importantes desse processo podem ser identificados: na gastronomia, como expressão da valorização e respeito com as tradições e hábitos das comunidades regionais; no turismo, como elemento que preserva e valoriza as raízes e identidades culturais. Apresentamos, ainda, a lógica do turismo como alternativa que permite abordar a influência dos fluxos, neste caso de turistas, de maneira positiva. Esta intenção pode conciliar os interesses econômicos com os interesses ligados à preservação patrimonial e fortalecimento das identidades culturais.

Por fim, concluímos que a culinária, nesse contexto, apresenta-se muito além do que apenas um conjunto de ingredientes e técnicas de transformação e preparação dos alimentos. Ela fortalece as raízes culturais e desenvolve os segmentos comerciais inter-relacionados ao meio rural e à gastronomia. Esse conjunto de fatores fornece atributos culturais que reforçam as bases territoriais para o desenvolvimento das regiões. No âmbito do patrimônio imaterial, o turismo pode contribuir para o revigoramento dos saberes e fazeres por intermédio do aumento da visibilidade dada pelo turismo. Tudo isso contribui para o fortalecimento das identidades culturais e de práticas socioculturais que, em alguns casos, poderiam estar sofrendo um processo de esquecimento. Logo, o turismo pode, por meio dos bens culturais, promover a valorização da cultura e da região com suas particularidades.

\section{DESENVOLVIMENTO DO CAPITALISMO E AS TENSÕES REGIONAIS}

O grande impulso promovido pelas modificações nos processos de produção desencadeados pelos conceitos de Henry Ford, em 1914, acabou revolucionando as técnicas de produção, gerando importantes transformações no sistema industrial; isto é, a divisão do trabalho na qual cada trabalhador era o responsável por uma determinada etapa do sistema produtivo, a criação de controles de trabalho e a implantação de tecnologias. Ford também implantou a jornada de trabalho de oito horas diárias, bem como o pagamento de cinco dólares, em recompensa ao trabaIho realizado pelo período (Harvey, 1992).

Estas importantes transformações acabaram fortalecendo a economia e fomentando o consumo, fazendo surgir a sociedade de consumo e a acumulação de capital. Naquele período, o desenvolvimento era entendido a partir do processo de industrialização, ou seja, quanto mais indústrias em uma determinada região, mais desenvolvida seria esta região. Nessa concepção, tendo a industrialização como sinônimo de desenvolvimento, tem-se o meio rural, julgado como um espaço atrasado e retrógrado. 
A partir das últimas décadas do século XX, quando o processo de produção/ acumulação fordista entra em crise, surge um novo regime de acumulação, contrapondo-se justamente à característica mais marcante daquele, que é denominado acumulação flexível. Desta forma, de acordo com Harvey (1992), a acumulação flexível origina-se na década de 1970, e tem como suporte obter certa flexibilidade nos processos de trabalho, nos padrões de consumo e nos produtos, confrontando diretamente a rigidez imposta pelo sistema fordista. Portanto, leva-se em consideração que o sistema fordista possuía um determinado grau de rigidez, exposto nos investimentos de capital fixo em sistemas de produção em massa, excluindo, assim, vários países do terceiro mundo, que não tinham condições de se inserir por completo neste sistema.

Na produção fordista e na acumulação flexível, embora distintas entre si, em parte a visão de desenvolvimento continuava relacionada à industrialização, e o espaço rural não teve sua avaliação alterada. Desta forma, Harvey (1992) considera que a crescente expansão do capitalismo no mundo amplia o espaço, podendo surgir assim o problema da superacumulação. Em decorrência disto, o resultado que se tem é o do deslocamento espacial do capitalismo, com um significativo aumento da competição inter-regional e internacional, gerando graves consequências nos territórios.

Essas tensões, por sua vez, acabaram por gerar grandes impactos nas regiões, dividindo o globo em regiões desenvolvidas e subdesenvolvidas. $O$ fato é que enquadrar os territórios em modelos "padrões" de desenvolvimento, trouxe sérios problemas em todas as dimensões, promovendo uma perda significativa de suas diversidades.

A partir desta premissa, de acordo com Sachs (2000, p.16), "é impossível falar de desenvolvimento sem se referir a conceitos tais como pobreza, produção, noção do estado ou igualdade". A promoção do desenvolvimento, sem estar atrelada ao processo industrial, ganhou significativas contribuições, principalmente a partir da segunda Guerra Mundial, em que o estudo sobre o desenvolvimento passa a ter um novo olhar, com a atenção para as dimensões sociais, culturais, políticas e ambientais. Assim, pode-se considerar que as últimas décadas foram importantes para a discussão acerca do significado do termo desenvolvimento e compreensões.

Sachs (1986) acrescenta que é preciso entender as formas de promover o desenvolvimento, sem focar apenas no crescimento, pois o crescimento, em si mesmo, não promove o desenvolvimento. $O$ entendimento de que o crescimento econômico deve ser repensado de forma adequada, com vistas a reduzir os impactos ambientais e sociais negativos no território, valorizando as características do espaço e 
dos atores regionais, continua sendo uma condição necessária para o desenvolvimento em todas as suas dimensões, completa Sachs (2000).

O desenvolvimento pode ser entendido como um processo dinâmico, presente no território, com dimensões que a cada momento são construídas e reconstruídas, através das relações sociais, econômicas e ambientais. Portanto, a globalização econômica é apresentada como um subproduto, a reação gerada pelo regional diante do global. De acordo com Santos (2002, p. 338 - 339):

A ordem global funda as escalas superiores ou externas à escala do cotidiano. Seus parâmetros são a razão técnica e operacional, o cálculo de função, a linguagem matemática. A ordem local funda a escala do cotidiano, e seus parâmetros são a co-presença, a vizinhança, a intimidade, a emoção, a cooperação e a socialização com base na contiguidade.

As transformações decorrentes desse processo possuem dimensões de ordem econômica, política, cultural, social e ambiental, que podem se transformar para satisfazer as mais diversas necessidades, até mesmo no que tange à alimentação dos grupos de atores de uma região ou àqueles que estão no território para explorar.

Nesse sentido, a promoção do desenvolvimento regional exige dos agentes diretamente envolvidos no processo, e da sociedade como um todo, a definição de um projeto político que aponte o caminho a ser trilhado (ETGES, 2001). Por desenvolvimento regional, Etges (2003, p. 67) entende "todo um processo de construção amparado na potencialização de capacidades endógenas".

O desenvolvimento, de acordo com Brandão (2009, p. 154),

é um processo multifacetado de intensa transformação estrutural resultado de variadas e complexas interações sociais que buscam o alargamento do horizonte de possibilidades de determinada sociedade. Deve promover a ativação de recursos materiais e simbólicos e a mobilização de sujeitos sociais e políticos, buscando ampliar o campo de ação a coletividade, aumentando sua autodeterminação e liberdade de decisão.

Em Benko (1999), encontramos a afirmação de que o desenvolvimento regional volta-se aos problemas da integração regional, e não possui apenas implicações econômicas, mas tem consequências políticas e culturais, tornando a região um produto social, construído pela sociedade nos espaços de vida.

A proposta neste sentido é promover um desenvolvimento de caráter econômico e social contínuo, harmonizado com a gestão racional do ambiente, estimulando, dessa forma, uma reestruturação de todos os objetivos e modalidades de ação. 


\section{GLOBALIZAÇÃO, INDUSTRIALIZAÇÃO DE ALIMENTOS E OS IM- PACTOS NA CULINÁRIA REGIONAL}

Nas últimas décadas, as regiões estão passando por grandes mudanças socioeconômicas e culturais, devido à globalização. Discorrendo sobre o tema, Azevedo (2001, p.27) afirma que essas mudanças são

decorrentes das ações que asseguram a emergência de um mercado dito global, que se sobrepõe aos espaços, como consequência de uma nova fase do sistema capitalista de produção, denominada de período técnico-científico-informacional ou de capitalismo tecnológico.

Destacamos que a influência da globalização nas culturas e valores, portanto, nas identidades, acontece por meio de transformações aceleradas da indústria e dos padrões de consumo, alimentados pela presença aguçada do modo de produção capitalista. Isto é, os processos de globalização repercutem diretamente na sociedade, resultando em alterações, desde o curto prazo, movidas pela consolidação dos processos de "modernização".

Nesse contexto, é crescente o aparecimento de discursos que abordam a homogeneização dos territórios e culturas, pois a compressão tempo-espaço está acelerada. As informações são pulverizadas, os transportes encurtam distâncias, e o capital não encontra mais barreiras, levando a ideia de que as culturas de consumo estão padronizadas e isso incide no território, fala-se em "aldeia global".

A globalização modifica fronteiras e sociedades, cria novos mapas, novos arranjos políticos e novas sociabilidades. O capitalismo global redimensiona os conceitos de espaço e tempo, produz uma quantidade enorme de vínculos assimétricos que mexem com estados inteiros e, por conseguinte, com o seu ordenamento social vigente e as suas identidades. (IICA, 2002, P. 12).

Para Santos (2002), a globalização constitui-se na fase mais avançada do processo de internacionalização do mundo capitalista. Etges (2005, p. 51) complementa, afirmando que

o processo de globalização está reordenando os territórios e que apresenta pelo menos duas faces: a da perversidade do processo em si, expressa na territorialização dos interesses dos segmentos hegemônicos, e a da oportunidade, que se apresenta aos atores regionais quando se apropriam de conhecimentos que lhes permitem reagir, superar a passividade.

Para Azambuja (1999, p. 15), o mundo contemporâneo está cada vez mais global, "e nos distanciamos a passos largos de nossas particularidades, de nossas raízes". As transformações decorrentes do modo de produção capitalista expressam-se, desde o século XVIII. Essas transformações também foram significativas na agricultura e 
no modo de produzir alimentos. Hernández (2005, p. 130) descreve que o processo de globalização promoveu o desaparecimento de muitas manifestações ou produções de caráter local e regional, "desde as variedades vegetais, animais, línguas, tecnologias e qualquer tipo de costumes e de instituições socioculturais. Enquanto umas desaparecem, outras se expandem e se generalizam".

Santos (1996) expõe a influência do Meio-Técnico-Científico-Informacional através da velocidade das informações e da compressão do espaço e do tempo, em que tudo se torna passageiro. É no contraponto a essa compressão que a cultura de uma sociedade, apropriada de suas memórias e identidades, deve procurar se destacar na luta de resistência à padronização global.

A esses entendimentos sobre as manifestações de caráter local e regional, Mintz (2001, p. 33) acrescenta que "a comida foi então um capítulo vital na história do capitalismo, muito antes dos dias de hoje: como alimentar as pessoas, e como fazer dinheiro alimentando-as". O autor afirma ainda que, a partir destas grandes mudanças, principalmente nas últimas décadas, as regiões assistiram à disseminação de alimentos e de novos sistemas de distribuição em todo o globo. E, através desses novos fatores, a chamada industrialização da alimentação está promovendo significativas transformações, não somente no modo das pessoas se alimentarem, mas principalmente nos sistemas de produção no meio rural, modificando as bases culturais e sociais.

Essas transformações no modo de produzir alimentos e nos hábitos alimentares fez surgir, segundo Pedroco (1998), uma nova fase no segmento da produção de alimentos em massa, fruto das inovações aplicadas à indústria de alimentos. Nesse processo, a produção de alimentos industrializados em massa acabou utilizando as inovações de conservação para disponibilizar aos consumidores produtos com uma vida útil maior, aumentando, dessa forma, a oferta de alimentos.

Maciel (2004) afirma que as grandes transformações tecnológicas facilitaram o consumo de alimentos industrializados e produzidos em massa, que hoje se tornam cada vez mais populares entre os consumidores; e essa expansão representa um fenômeno mundial. Tais alimentos, frequentes nas mesas das famílias, acabaram modificando a estrutura alimentar e as tradições culinárias, elementos que emolduram e diferenciam as culturas. Além disso, causaram uma importante perda de saberes em termos gastronômicos.

Mintz (2001) é categórico ao afirmar que é cada vez mais comum a busca pelo consumo de alimentos congelados ou pré-preparados, encontrados em qualquer supermercado ou casa comercial. Essa realidade não promove somente o empobre- 
cimento do conhecimento sobre as técnicas e habilidades culinárias, mas também o enfraquecimento do caráter simbólico, social e histórico que a alimentação carrega entre os indivíduos.

Essa grande disponibilidade de alimentos industrializados, segundo Silva e Etges (2012), se deve à modernização dos sistemas de produção agrícola, neste caso, o agronegócio, que tem por objetivo somente a produtividade em grande escala e a busca por excelentes resultados econômicos e financeiros em curto prazo. Para os autores, o sistema de plantio em grande escala promove a produção das chamadas monoculturas, que são plantações especializadas na alta produtividade de grãos, como a soja, o milho e o arroz, baseada na utilização de aditivos químicos e com a sua produção destinada ao mercado externo. Igualmente, a modernidade agrícola e alimentar visa, conforme afirma Hernández (2005, p. 134), "a superespecialização do espaço, a busca constante dos aumentos dos lucros nas produções agrárias, o crescimento expressivo das cidades e as "desertificações" das zonas rurais".

O meio rural, nesse sentido, e de acordo com Silva e Etges (2012), deve ser considerado um espaço destinado às práticas agrícolas, e não apenas um local de produção de mercadorias; mas, principalmente, deve ser entendido como um meio no qual ocorre a produção da vida, que se dá através das relações de cooperação, reciprocidade e comprometimento do proprietário com a terra.

O alimento moderno, como nos aponta Poulain (2004), está deslocado, desconectado do seu enraizamento geográfico, que lhe foi tradicionalmente associado, durante muito tempo. Novo da Silva, Schwartz e Menasche (2013, p. 96) descrevem que, a partir do processo de globalização e de homogeneização, as regiões e os territórios se organizam de forma a reverter as consequências causadas e buscam "uma espécie de (re) afirmação do local, de especificidades, uma (re) valorização de características locais, de processos endógenos".

É na busca pela particularidade, pelo desenvolvimento de regiões, pelo espaço da diferença que nascem processos de resistência, caminhos que procuram a afirmação das identidades culturais frente à globalização. Esta que é um processo de integração diferenciado e desigual. Ainda assim, promove a integração, e nesse contexto as identidades se afirmam em contraposição a esse movimento integrador.

As transformações no sistema de alimentação moderna e produção de alimentos em massa, de acordo com Carneiro (2003), sob a hegemonia das grandes redes de supermercados, dos estabelecimentos de fast foods e dos restaurantes, acabaram suprimindo os espaços das cozinhas regionais e domésticas e todos os saberes que permeavam esses lugares. De acordo com Santos (2009), os hábitos alimentares 
globalizados atuais têm avançado fortemente em diversos lugares do mundo, ainda que tal inovação esteja fundamentada, na maioria das vezes, nos discursos sobre a saúde e bem estar e, principalmente, no aspecto comercial.

Assim, percebe-se que o sistema culinário atual expressa, em sua complexidade, essa nova dinâmica; e os resultados e oportunidades que derivam desse processo atuam fortemente no território como movimentos de resistência e afirmação de sua tradição e história. O saber fazer local, conforme descreve Santos (2002), é uma forma de expressão cultural realizada pelas relações dos indivíduos e de seus grupos, que tem por objetivo promover a valorização da identidade da cultural regional. Neste sentido, para Flores (2006, p. 10),

as sociedades podem ser estimuladas a explorar seu potencial territorial e o saber fazer local, através de um processo de construção coletiva através da cooperação, cujo resultado poderia ser a diferenciação de produtos com qualidade para o mercado.

A culinária regional, nesse contexto, pode ser compreendida, segundo Atala \& Dória (2008), como "um espaço de pertencimento", no qual há de se considerar que essas raízes de pertencimento fazem parte da história do povo, que usa o território e nele produz uma infinidade de sabores, desenvolvendo um conjunto de técnicas de conservação e de preparo dos alimentos. Essas características são saberes que integram a riqueza e o patrimônio cultural gastronômico regional.

Bell e Valentine (1997) complementam, esclarecendo que este tipo de cozinha é construída a partir da herança cultural que dialoga com as fronteiras e identidades territoriais solidificadas no imaginário popular; submetidas, no entanto, a novos arranjos. Atala \& Dória (2008) afirmam ainda que determinados territórios atribuem propriedades específicas aos seus produtos e, por isso, merecem uma evidência e uma atenção especial, por parte da gastronomia, e também de todos os atores regionais. Nessa mesma linha, Azevedo $(2011$, p.50) destaca que

fica clara a importância das culinárias locais no contexto atual. Essa discussão não se limita em falar de prazeres gustativos, mas de representações simbólicas que envolvem a estruturação de uma identidade territorial a partir da culinária. Isso porque acreditamos que ela é um elemento de demarcação cultural, consequentemente, territorial.

Petrini (2009) acrescenta que a culinária de determinada região é tanto produto da natureza como da cultura, é um poderoso meio de pensar quem somos. O deslocamento até a região e a degustação in loco da comida daquele local, é parte dessa nova experiência. Território e especificidade culinária passam a dominar a ideia de cozinha regional e se transformam em estímulo aos viajantes, que saem da cidade em busca da verdadeira comida. 
Menasche et al. (2008, p.147) complementam, ao afirmarem que

\begin{abstract}
a comida pode, então, ser tomada como linguagem, como texto cultural que fala do corpo, da família, do trabalho, de relações sociais, de visões de mundo, agindo diretamente na relação de pertencimento de seus atores locais, e faz com que estes expressem sua identidade a partir das relações presentes no ato da alimentação.
\end{abstract}

Nesse contexto, a valorização dos saberes e práticas alimentares estão diretamente relacionadas à construção de uma identidade cultural. $\mathrm{O}$ ato de comer um prato típico, local ou regional, carregado de tradição, cada vez mais traduz a crescente valorização das particularidades regionais, principalmente levando em consideração quem o produziu e como foi produzido. Isto faz com que "em tempos de globalização, como certo paradoxo, temos a volta do frango e dos ovos caipira, a busca de alimentos orgânicos, a valorização da broa preta, a reutilização e a revalorização da panela de ferro, e outros" (SANTOS, 2009, s/r).

Assim, a culinária regional, além de ser importante instrumento de valorização e preservação de saberes e sabores, tem por objetivo contribuir economicamente, através da produção e comercialização de produtos agrícolas sem a adição de produtos químicos. Os alimentos típicos, nesse sentido, fornecem atributos culturais que fortalecem as bases territoriais para o desenvolvimento de uma região, que vai repercutir também na promoção das atividades turísticas e na comercialização de produtos típicos regionais.

Ao preservar os saberes e fazeres e o patrimônio cultural e ao valorizar a identidade, não só estabelece conexão com a dinâmica global, através da atividade turística; mas, ao mesmo tempo, fortalece seus laços regionais como atitude contrária à primeira ordem padronizadora da globalização.

Diante destas considerações, pode-se afirmar que a culinária regional é carregada de saberes, práticas, características culturais e sociais que acabam transformando e valorizando o território. Desta forma, a culinária passa a ser considerada patrimônio imaterial que, conforme Vogt (2008), tem por objetivo conservar a história e a memória de um povo, assegurando a preservação de sua identidade. A culinária regional deixa marcas no imaginário dos indivíduos que a provam e compartilham.

Portanto, rico em significados e importante para a sociedade, o patrimônio cultural apresenta grande potencial para a prática do turismo. O turismo, como atividade econômica importante na conjuntura mundial, possui implicações sociológicas, econômicas e geográficas que marcam a sua complexidade, uma vez que essa atividade também é considerada como um dos principais vetores de aproximação de culturas e identidades. 


\title{
4. A GASTRONOMIA REGIONAL E O TURISMO COMO ELEMENTOS FORTALECEDORES DA IDENTIDADE CULTURAL FRENTE À TENSÃO ENTRE O GLOBAL E O REGIONAL
}

De uma perspectiva mais ampla, cultura envolve o meio natural, no qual o homem vive e se relaciona; o saber fazer, elementar à existência e perpetuação do homem; e os bens culturais, feitos a partir das ações humanas.

De acordo com Laraia (1997), cultura é um conjunto de valores, crenças, costumes, hábitos e fatores históricos materiais e imateriais que permeiam, de forma dinâmica, a vida social. Ou seja, a cultura é construída ao longo de processos históricos e materiais de um povo, através de suas relações e modos de vida, vistos de uma concepção antropológica de cultura.

Na relação entre cultura e identidade, é preciso evidenciar o papel do patrimônio cultural como suporte da história e memória dos grupos sociais. Dessa forma, o patrimônio torna-se elemento essencial na construção da identidade cultural, seja coletiva ou individual. E, igualmente, é possível considerá-lo como a materialização das identidades.

Hall (2003) descreve que a identidade é marcada por meio de símbolos e significações. A prática de significação produz um sentido de relações e disputas de poder para definir o que é incluído e quem é excluído. A construção da identidade ocorre também através das relações estabelecidas com o território.

Para Montanari (2009, p.12),

\begin{abstract}
as identidades culturais não estão inscritas no patrimônio genético de uma sociedade, mas incessantemente se modificam e são redefinidas, adaptando-se a situações sempre novas, determinadas pelo contato com culturas e identidades diversas.
\end{abstract}

O autor complementa ainda que as identidades não existem sem trocas culturais e que elas se conectam através dos movimentos de proteção. De acordo com Vendruscolo e Froehlich (2007), a formação de identidades se configura a partir das relações sociais estabelecidas nos espaços de sociabilidade, sendo assim, construídas a partir de um processo de afirmação e de diferença.

Woodward (2000) acrescenta que a identidade é relacional, bem como é marcada pela diferença e, por vezes, envolve a negação pela falta de similaridade. Nesse sentido, a identidade acaba estabelecendo limites simbólicos, e se manifesta nas relações entre grupos. $\mathrm{O}$ indivíduo se torna sujeito a partir das relações que mantém com o outro, ou seja, através da troca existente entre o que eu sou e o que o outro é. Logo, pode-se considerar que as identidades surgem a partir das relações de pertencimento. 
A importância da preservação do patrimônio surge justamente da sua contribuição para manter e preservar a identidade de uma sociedade, um grupo, comunidade, família e outros. É a herança do passado que, vivenciada pelas gerações atuais, será propagada às próximas gerações.

Uma comunidade local, como já se indicou, tende a atribuir um valor simbólico a alguns elementos da paisagem, reconhecendo-os como expressão tangível da própria identidade territorial. A atribuição destes valores simbólicos se funda quase sempre sobre a imagem que a comunidade local (insiders) possui de si mesma e da própria especificidade territorial e, por consequência, nem sempre encontra uma correspondência na percepção dos outsiders (POLLICE, 2010, p. 13).

Entretanto, o patrimônio é uma construção social e, frequentemente, o que está preservado e é mais difundido, é apenas uma versão do conjunto de ações humanas de um determinado período. Nesse caso, observando a relação direta entre identidade e patrimônio, a construção da identidade coletiva é um processo seletivo e fragmentado. Barretto (2001, p.13) explica que determinar o que é digno de preservação é uma decisão político-ideológica, que reflete valores e opiniões sobre as quais são os símbolos que devem permanecer para retratar determinada sociedade ou momento.

Assim sendo, independentemente dessa discussão, a sociedade constrói e reproduz a sua identidade, através do apego constante ao seu passado, ou seja, os bens do patrimônio cultural.

A identidade é dinâmica, muda no tempo à semelhança de todas as outras componentes territoriais e do território no seu complexo. A identidade apresenta uma variabilidade elevada em termos tanto temporais quanto espaciais; antes, tal variabilidade tende a ser maior na dimensão temporal do que aquela espacial (POLLICE, 2010, p.11).

Assim, podemos considerar que conceito de patrimônio tem vários significados. O mais comum é conjunto de bens que uma pessoa ou uma entidade possuem. De acordo com Barretto (2001), o patrimônio pode ser classificado em duas grandes divisões de natureza e cultura. Patrimônio natural pode ser conceituado como o montante de riquezas que estão presentes no solo e no subsolo, enquanto o patrimônio cultural são os bens culturais, resultantes das ações humanas e que se agregam à natureza. É também uma forma de ser, pensar e atuar em uma sociedade.

Barretto (2000, p.11) ainda afirma que "a noção de patrimônio cultural é muito mais ampla, e que não inclui apenas os bens tangíveis como também os intangíveis e todo o legado cultural, o saber fazer humano, que representa a cultura de um território". Vogt (2008, p.14) descreve que: 
o patrimônio cultural é definido como conjunto de todos os bens materiais ou imateriais, que, pelo seu valor intrínseco, são considerados de interesse e de relevância para a permanência e a identificação da cultura da humanidade, de uma nação, de um grupo étnico ou de um grupo social específico.

O patrimônio imaterial é relatado por Vogt (2008, p.14) como um conjunto de costumes como, por exemplo:

as maneiras de vestir, hábitos alimentares, instrumentos musicais, obras de arte, técnicas construtivas, monumentos, máquinas e equipamentos, móveis, moedas e outros bens de uma sociedade. O patrimônio imaterial é constituído por canções, crenças, celebrações, ritos, lendas; por saberes que passam de uma geração para outra, como as formas de cultivar e as maneiras de produzir, a linguagem para se comunicar; por manifestações cênicas, lúdicas e plásticas; por lugares e espaços de encanto e de convívio e encontro de uma sociedade.

Neste sentido, a culinária regional é carregada de características culturais e sociais, não obstante ela possa ser considerada um patrimônio imaterial, pois, de acordo com Azevedo (2001), ela deixa marcas no imaginário dos indivíduos que a provam e compartilham. Nesse sentido, a gastronomia se torna um importante elemento de ligação do comensal com o território e o espaço regional, e faz, ainda que por um momento, esse indivíduo se tornar parte daquele território.

Nesse sentido, para Barretto (2007), turismo cultural é todo turismo no qual o principal atrativo não é a natureza, mas um aspecto da cultura, qualquer um dos aspectos abrangidos pelo conceito de cultura. Portanto, a atividade turística pode se tornar um elemento potencial para promover a manutenção e preservação de tradições culturais.

A partir da perspectiva cultural do turismo, o patrimônio cultural, o qual era visto apenas como representação do passado, adquire novas proporções. O patrimônio pode ser visto como elo entre memória e identidade, como motor fundamental para desencadear o processo de identificação do cidadão com a sua história e sua cultura, despertando o interesse pelo compartilhamento de experiências com visitantes. Igualmente, o patrimônio promove a ampliação de conhecimentos e o respeito entre as sociedades (BARRETTO, 2001).

Nesse contexto, surgem duas possibilidades: a promoção e utilização com vistas à preservação do bem ou, por outro lado, à padronização e distorção do bem para satisfazer a indústria do consumo de massa. A segunda possibilidade mostra o lado perverso da atividade turística, caracterizada por impactos negativos e falta de planejamento adequado.

O planejamento turístico torna-se imprescindível para que os atrativos culturais não sejam vistos como meras mercadorias, simples fonte de exploração e renda, 
mas sim como o legado cultural das gerações passadas para as futuras. O turismo deve valer-se dos bens culturais, promovendo a valorização destes através das suas particularidades.

\section{CONSIDERAÇÕES FINAIS}

Os fluxos promovidos pela globalização nem sempre são harmoniosos; de fato, em sua maioria, são permeados por tensões e forças originadas pela lógica do modelo de econômico hegemônico, o qual fundamenta-se apenas no aspecto econômico. Esses processos produzem transformações na autenticidade e identidade cultural das sociedades em todo o mundo.

As grandes transformações do mundo atual, favorecidas pela globalização, causaram importantes transformações que influenciaram as dimensões espaciais, sociais, e culturais nas regiões, atingindo também a agricultura e o modo de produzir alimentos, causando uma onda de transformações no meio rural. Não obstante a globalização, a partir da abertura dos mercados e da industrialização da alimentação, permitiu que todos os objetos de consumo, inclusive os alimentos, passassem a ser distribuídos por todas as partes do globo, possibilitando ao consumidor adquirir bens de consumo dos quais não sabe a procedência, nem as condições sociais e ambientais em que foram produzidos.

Assim, pode-se destacar que, paradoxalmente, essa dominação econômica, na atualidade, não está preocupada com o desenvolvimento econômico, social e cultural de uma região, muito embora ela influencie os territórios, alterando atitudes, valores, modificando e miscigenando culturas, padronizando gostos, saberes, que são características da identidade sociocultural de uma região. Dessa forma, modifica as regiões, implicando na perda de suas características históricas e culturais.

Neste sentido, o desenvolvimento regional, além de produzir transformações de ordem econômica, social e cultural nos territórios, procura também valorizar e resgatar os traços culturais das identidades de determinada região.

Portanto, ao preservar o patrimônio cultural e valorizar a identidade, o lugar estabelece conexão com a dinâmica global, através da atividade turística, e fortalece, localmente, seus laços com a sua cultura. Por fim, o patrimônio cultural é o elo do homem com a prática social, uma vez que, como mediador entre o passado e o presente, ancora a construção da identidade cultural. Assim, rico em significados e importante para a sociedade, o patrimônio cultural se traduz como diferencial dos lugares e das regiões para o desenvolvimento do turismo. 


\section{REFERÊNCIAS BIBLIOGRÁFICAS}

ATALA, Alex; DÓRIA, Carlos Alberto. Com unhas, dentes e cuca: prática culinária e papo-cabeça ao alcance de todos. São Paulo: Ed Senac, 2008.

AZAMBUJA, Lissi Bender (Org.). Forno e fogão: como no tempo de nossos avós = Kochen und Backen : Wie Unsere Grosseltern. Santa Cruz do Sul: EDUNISC, 1999.

AZAMBUJA, Lissi Bender (Org.). Forno e fogão: para dias festivos = Kochen und backen für feierliche tage. Santa Cruz do Sul: EDUNISC, 2001. 153 p.

AZEVEDO, Jucicléa M. de. Culinária do Seridó: um elemento da identidade territorial /Jucicléa Medeiros de Azevedo. - 2011.

BARRETTO, Margarita. Cultura e turismo. Campinas: Papirus, 2007.

BARRETTO, Margarita. Turismo e legado cultural: as possibilidades do planejamento. 2. ed. Campinas: Papirus, 2001.

BELL, David; VALENTINE, Gill. Cosuming geographies. London: Routledge, 1997.

BENKO, G. Economia, espaço e globalização na aurora do século XXI. 2ª̣ed. São Paulo: Hucitec, 1999.

BRANDÃO, C. Desenvolvimento, territórios escalas espaciais: levar na devida conta as contribuições da economia política e da geografia crítica para construir a abordagem interdisciplinar. In: Compreendendo a complexidade socioespacial contemporânea: o território como categoria de diálogo interdisciplinar / Maria Teresa Franco Ribeiro, Carlos Roberto Sanchez Milani (Organizadores). - Salvador : EDUFBA, 2009. CARNEIRO, Henrique S. Comida e sociedade. Uma história da alimentação. Rio de Janeiro-RJ: Campus, 2003.

ETGES, V. E. Desenvolvimento Regional sustentável: o território como paradigma. In: REDES. Santa Cruz do Sul, v. 10, n. 3, p. 47-55, set./dez. 2005.

ETGES, Virginia E. A região no contexto da globalização: o caso do Vale do Rio Pardo. In: VOGT, O.; SILVEIRA, R. Vale do Rio Pardo: reconhecendo a região. Santa Cruz do Sul: Edunisc, 2001.

FLORES, Murilo. A identidade cultural do território como base de estratégias de desenvolvimento - Uma visão do estado da arte. Santiago-Chile: RIMISP, 2006. Disponível em: <http://www.rimisp.org/getdoc.php?docid=3702>. Acesso em: 05 jan. 2014.

HALL, Stuart. A identidade cultural na pós-modernidade. 7. ed. Rio de Janeiro: DPA, 2003. 
HARVEY, David. A transformação político-econômica do capitalismo do final do sec. XX. Condição pós-moderna. São Paulo, 1992.

HERNÁNDEZ, J. C. Patrimônio e Globalização: o caso das culturas alimentares. CANESQUI, Ana Maria (Org.) Antropologia e nutrição: um diálogo possível. Organizado por Ana Maria Canesqui e Rosa Wanda Diez Garcia. Rio de Janeiro: Editora FIOCRUZ, 2005. IICA - Instituto Interamericano de Cooperação para a Agricultura. Documento de síntese do seminário internacional. Realizado em 24, 25 e 26 de setembro de 2002. São Luiz-Maranhão.

LARAIA, Roque de Barros. Cultura: um conceito antropológico. 11. ed. Rio de Janeiro: J. Zahar, 1997.

MACIEL, Maria Eunice. Churrasco à Gaúcha. In: MONTEBELLO, N. de P.; COLLAÇO, J. H. L. Cortes e Recortes. 2. ed. Brasília: Editora SENAC-DF, 2009.

MACIEL, Maria Eunice. Cultura e alimentação ou o que tem a ver os macaquinhos de koshima com Brillat-Savarin? In: Horizontes Antropológicos. Porto Alegre, ano 7, n.16, p.145-156, 2001.

MACIEL, Maria Eunice. Uma cozinha à Brasileira. In: Estudos Históricos. Rio de Janeiro, $n^{\circ} 33$, jan.-iun. 2004, p. 25-39.

MENASCHE, R.; MARQUES, F. C.; ZANETTI, C. Autoconsumo e segurança alimentar: a agricultura familiar a partir dos saberes e práticas da alimentação. Rev. Nutrição. Campinas, 21 (Suplemento), jul./ago., 2008, p. 145-158.

MINTZ, Sidney W. Comida e antropologia: uma breve revisão. Revista brasileira de Ciências sociais. Soc. [online]. 2001, vol.16, n.47, pp. 31-42. Disponível em: $<$ http://www.scielo.br/scielo.php?pid=S0102-69092001000300002\&script=sci_ arttext\&tlng=pt>. Acesso em: 29 mai. 2013.

MONTANARI, M. A cozinha, lugar da identidade e das trocas. In: MONTANARI, M. O mundo na cozinha: história, identidade, trocas. Tradução Valéria Pereira da Silva. São Paulo-Estação Liberdade: Senac, 2009.

NOVO DA SILVA, F.; SCHWARTZ, L. H.; MENASCHE, R. O tradicional e o moderno na alimentação de famílias rurais pomeranas. Revista de la Facultad de Agronomía (La Plata). v. 112, p. 93-102, 2013.

PEDROCO, G.; A Indústria alimentar e as novas técnicas de conservação. In: FLANDRIN, J. L, MONTANARI, M. História da Alimentação. 2. ed. São Paulo: Estação Liberdade, 1998. PETRINI, Carlo. Slow Food: princípios da nova gastronomia. Tradução de Renata Lucia Botini. São Paulo: Editora Senac, 2009. 
POLLICE, Fabio. O papel da identidade nos processos de desenvolvimento local. In: Espaço e Cultura. Rio de Janeiro: UFRJ, n. 27, p. 7-23, jan./jun. de 2010.

POULAIN, J. P. Sociologias da alimentação: os comedores e o espaço social alimentar. Florianópolis: UFSC, 2004.

SACHS, I. Ecodesenvolvimento: Crescer sem destruir. São Paulo: Ed. Vértice, 1986.

SACHS, Wolfgang. Dicionário do desenvolvimento: guia para o conhecimento como poder. Tradução Vera Lúcia M. Joscelyne, Susana de Gylokay e Jaime A. Clasen. Petrópolis, RJ: Vozes, 2000.

SANTOS, C.R.A. O Império Mcdonald e a Mcdonalização da Sociedade: Alimentação, Cultura e Poder. Seminário facetas do império na história. 2006. Disponível em: http://people.ufpr.br/ andreadore/antunes.pdf. Acesso em: 04 de junho de 2013.

SANTOS, Milton. A natureza do espaço: técnica e tempo, razão e emoção. São Paulo: Edusp, 2002.

SANTOS, Milton. Por uma outra globalização: do pensamento único à consciência universal. 11. ed. Rio de Janeiro: Record, 2004.

SANTOS, Milton. Técnica, espaço, tempo: globalização e meio técnico-científico informacional. 2. ed. São Paulo: HUCITEC, 1996.

SANTOS. C. R. A. dos. Prefácio. In: Cortes e Recortes/ Nancy de Pilla Montebello, Janine Helfst Leicht Collaço. 2. ed. Brasilia: Editora SENAC-DF, 2009.

SILVA, R. do N.; ETGES, V. E. Do campo à mesa: reflexões sobre agricultura familiar e gastronomia. In: REDES - Revista do Desenvolvimento Regional. Santa Cruz do Sul, v.17, n. 3, p. 142-153, set./dez. 2012.

VENDRUSCOLO, R.; FROEHLICH, J. M. A construção social da identidade territorial da Quarta Colônia - tramas e sentidos da narrativa . In: FROEHLICH, José Marcos (Org.). Desenvolvimento Territorial - Produção, Identidade e Consumo. ljuí: Editora Unijuí, 2007

VOGT, Olgário P. Patrimônio cultural: um conceito em construção. MÉTIS: história e cultura, v. 7, n. 13, p. 13-31, jan./jun. 2008.

WOODWARD, Kathryn. Identidade e diferença: uma introdução teórica e conceitual. In: SILVA, Tomaz Tadeu da (Org.). Identidade e diferença - A perspectiva dos estudos culturais. Petrópolis: Vozes, 2000. 